\title{
PRIKUPLJANJE INFORMACIJA ZA IZRADU GIS-A METODAMA AUTOMATSKE DIGITALNE FOTOGRAMETRIJE
}

\author{
Miroslav Marčet \\ Visoka građevinsko-geodetska škola - Beograd
}

\section{Abstract:}

Geografski informacioni sistem (GIS) je kompjuterizovan sistem za prikupljanje, analizu i upravljanje geoprostornim podacima. Podaci o prostoru, smešteni u odgovarajuće baze podataka, predstavljaju glavnu komponentu GIS-a. Masovna akvizicija geoprostornih podataka najekonomičnije i najbrže se izvodi metodama digitalne fotogrametrije. Danas se intenzivno razvijaju automatski postupci digitalne fotogrametrije za prikupljanje geoinformacija o prostoru.

\section{Key words:}

geografski informacioni sistem, digitalna fotogrametrija,

korelacija slika,

digitalni model terena.

\section{UVOD}

Geografski informacioni sistem (GIS) je kompjuterizovan sistem za prikupljanje, analizu i upravljanje geoprostornim podacima. Najvažnija komponenta GIS-a su podaci o prostoru na koji GIS odnosi.

Geometrijske informacije o prostoru, georeferencirane na prostor za koji se GIS gradi, smeštaju se u bazu podataka kao različiti tematski slojevi Sl.1.

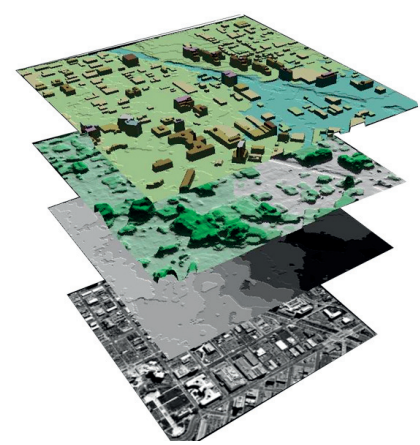

Sl.1 Baza podataka GIS-a - različiti tematski slojevi

GIS predstavlja prostor i informacije o njemu na dva, suštinski različita, načina, i to:

- na osnovu vektorskih podataka (tačka, linija, površina, itd.)

- na osnovu rasterskih podataka (digitalne karte i planovi, satelitski, aero i radarski snimci, bliskopredmetni snimci, itd)

\section{PRIKUPLJANJE GEOINFORMACIJA}

Prikupljanje geoinformacija o prostoru može se izvoditi geodetskim merenjima po terenu na osnovu kojih se izrađuju karte i planovi, ali i savremenim geodetskim metodama, kao što su: skeniranje prostora iz aviona (Sl.2), bliskopredmetno 3D-skeniranje (Sl.3) i fotogrametrijska metoda.

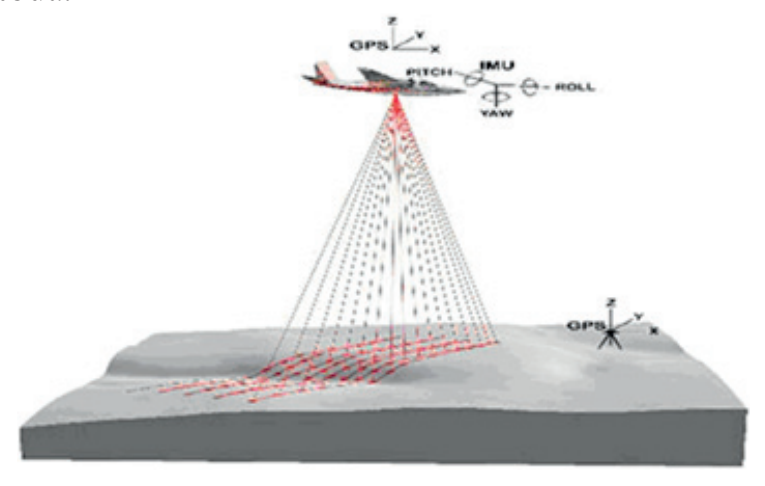

Sl.2 Lidar - skeniranje Zemljine površine iz aviona

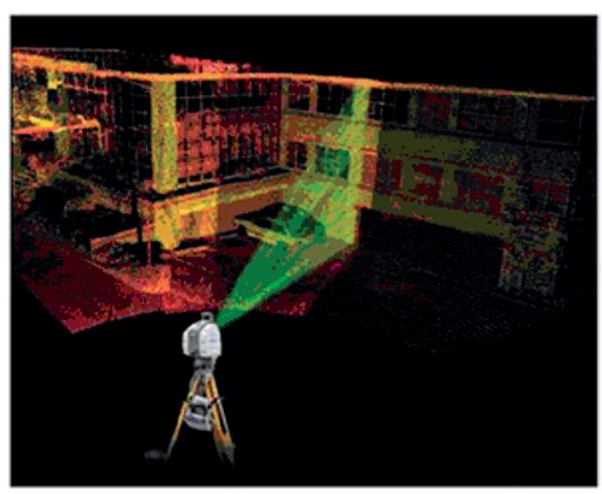

Sl.3 - 3D terestričko skeniranje prostora

S obzirom da se pri izgradnji nekog GIS-a zapravo radi o ogromnom broju geoinformacija i geopodataka koji se nalaze na prostoru za koji se GIS gradi, možemo zaključiti da je fotogrametrijska metoda najbrži i najekonomičniji način masovnog prikupljanja podataka za njegovu izgradnju. 
Ova metoda bazira na merenju i analizi satelitskih, aero i radarskih snimaka, ali i snimaka snimljenih sa bliskog rastojanja sa zemlje i iz vazduha.

Satelitski i aerosnimci prikazuju velike površine terena čijim merenjem se omogućava akvizicija ogromnog broja geoinformacija o snimljenom prostoru.

Tako merenjem ovakvih snimaka (nekada analognih a danas uglavnom digitalnih) dolazimo do velikog broja geometrijskih podataka, a na osnovu njih i do različitih karata i planova snimljene površine terena.

Proces merenja i analize fotogrametrijskih snimaka nekada se izvodio manualnim merenjem analognih (foto) snimaka Zemljine površine (Sl.4), dok se danas proces merenja izvodi poluautomatski ili automatski na elektronskim računaraima (Sl.5), a uz korišćenje digitalnih fotogrametrijskih snimaka.
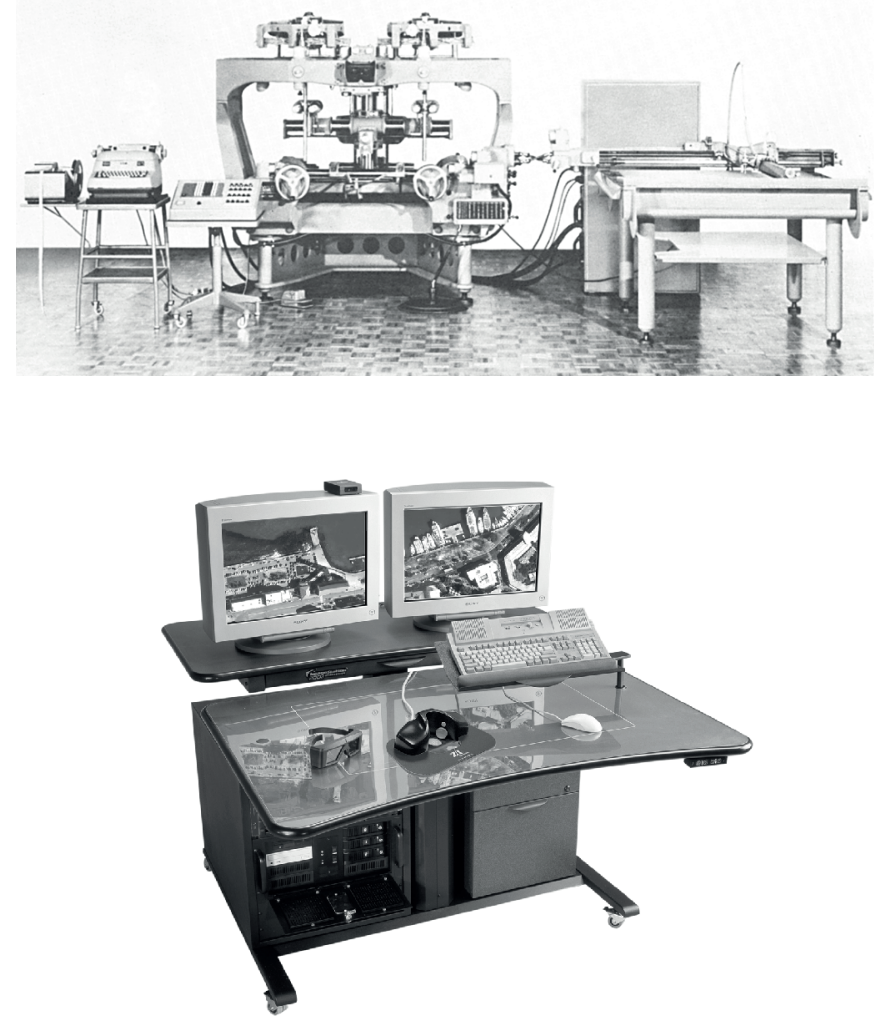

Sl.4 -Analogna restitucija - merenje fotosnimaka Zemljine površine Sl.5 - Digitalna fotogrametrijska radna stanica

Mereni podaci sa snimaka moraju se najpre georeferencirati na prostorni koordinatni sistem budućeg GIS-a. Zbog toga je neophodno poznavati prostorne koordinate određenog broja tačaka terena, čije slikovne koordinate merimo na snimku.

Određivanje prostornih koordinata ovakvih tačaka nekada se izvodilo isključivo geodetskim merenjima direktno na terenu, dok danas postoje poluautomatski i automatski postupci i metode bazirane na GPS-tehnologiji pozicioniranja kamere u toku snimanja i automatskog "on-line" određivanju prostornih rotacija svakog snimka $(\mathrm{K}, \Phi, \Omega)$.

Ovakvim postupkom merenja i obrade digitalnih snimaka dolazimo do slojeva baze podataka nekog GIS-a, i to:
- Linijski plan i katrta:

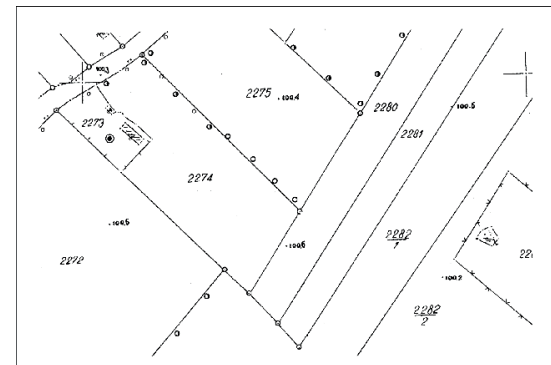

Sl. 5. Plan u linijskom obliku

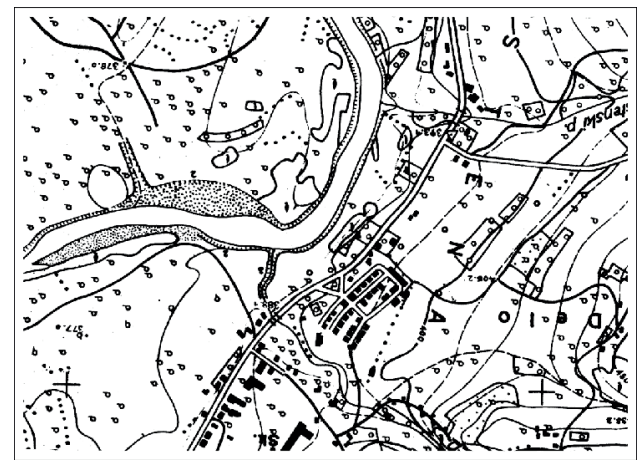

S1. 6. Karta u linijskom obliku

- Digitalni model terena dobijen na osnovu izmerenih 3D-koordinata velikog broja tačaka terena i njihove interpolacije:
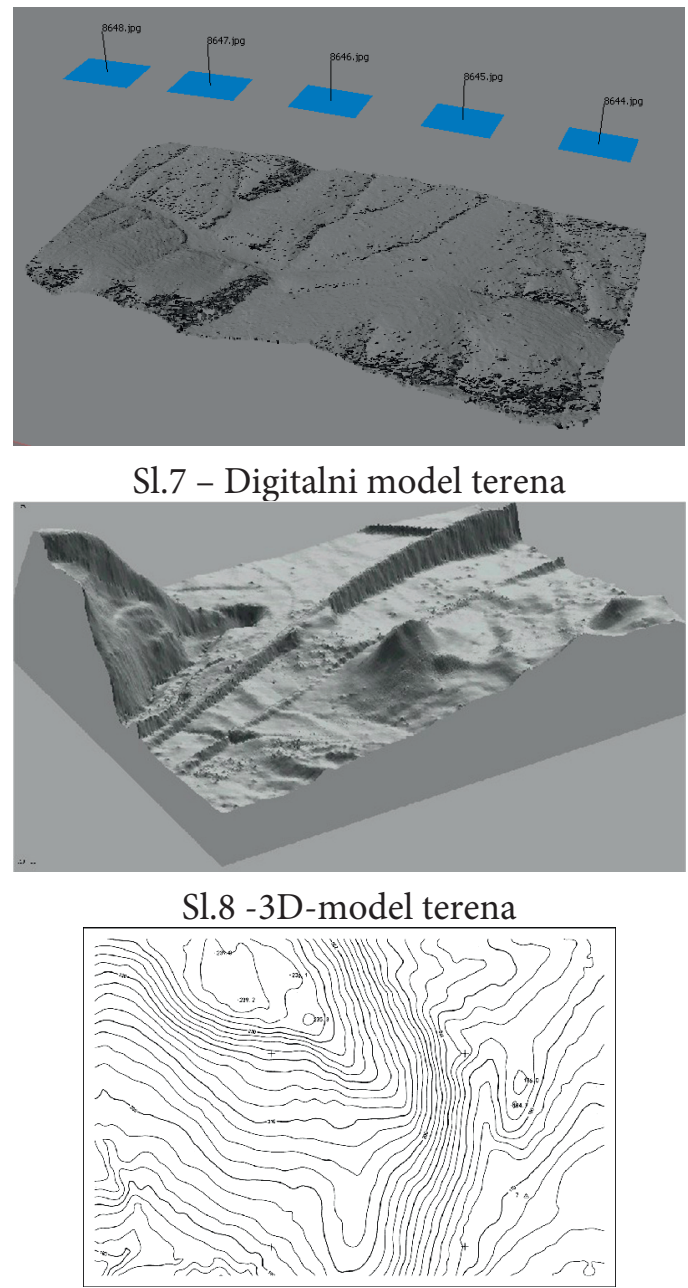

Sl.9 - Digitalni model terena predstavljen izohipsama 
- Digitalni ortofoto karta ili plan - plan ili karta u obliku fotoslike dobijen na osnovu automatske ortorektifikacije svakog piksela digitalne slike od koga ortofoto potiče

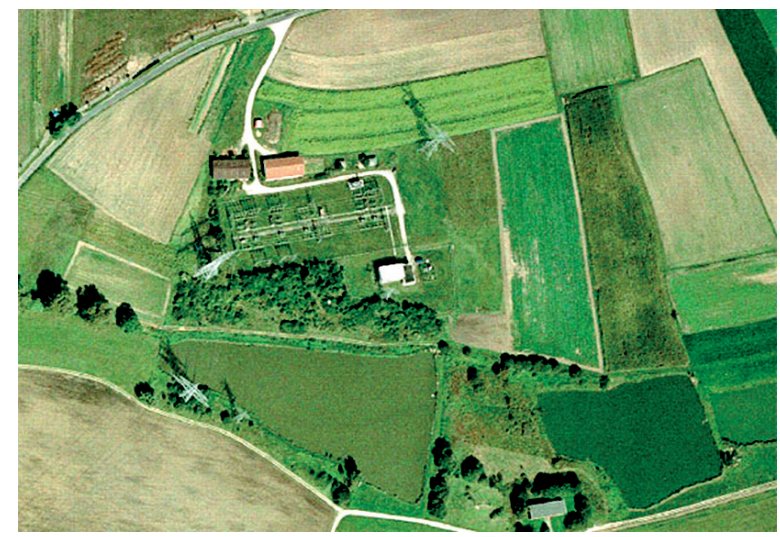

Sl.10 - digitalni ortofoto

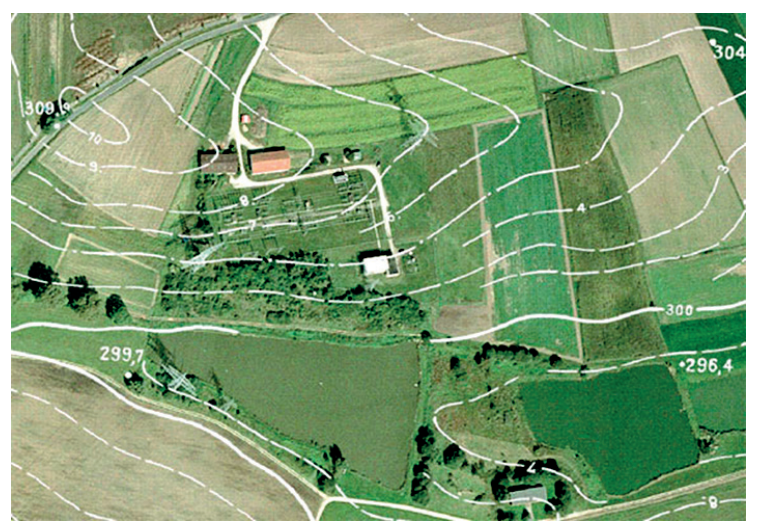

Sl.11 - digitalni ortofoto sa digitalnim modelom terena

Danas se merenje (prikupljanje) geoinformacija sa digitalnih snimka dela Zemljine površine za koji se gradi neki GIS odvija poluautomatski ili automatski, a procesom upravlja operator - restitutor.

Pri poluautomatskom prikupljanju geoinformacija restitutor mono ili stereoskopski poentira detalje na snimcima i automatski ih transformiše u prostorni koordinatni sistem GIS-a.

\section{AUTOMATIZACIJA PROCESA PRIKUPLJANJA GEOINFORMACIJA O PROSTORU}

Digitalna tehnologija u oblasti snimanja Zemljine površine i njihovo korišćenje za masovno prikupljanje podataka o prostoru omogućava sve veću automatizaciju ovog procesa. Tako je danas moguće pri merenju digitalnih snimaka isključiti restitutora (sa svim njegovim subjektivnim osobinama), te postići mnogo veću brzinu prikupljanja ogromnog broja geopodataka sa snimaka uz veću i homogeniju tačnost podataka.

Teoretska osnova pomenutog automatskog merenja, digitalnih snimaka, pa i njihove analize bez učešća restitutora, leži u tz. "korelaciji" digitalnih stereoparova snimljenog terena (stereopar - dva snimka istog dela terena koji su snimljeni sa krajeva neke baze, Sl.12, sukcesivni stereoparovi pri aerosnimanju Sl.13, koji se formiraju od susednih snimaka nekog niza aerosnimaka).

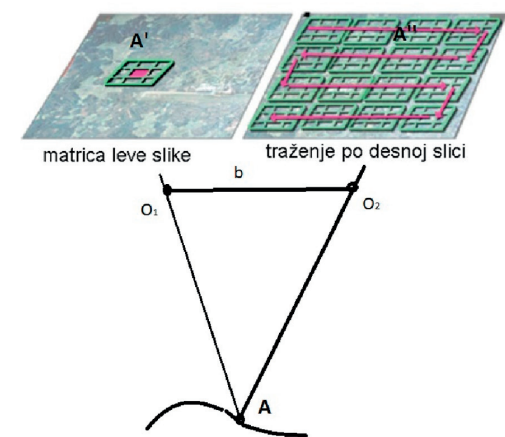

Sl.12 - princip korelacije digitalnih slika koje čine stereopar

Cilj korelacije snimaka jednog stereopara je automatsko određivanje slikovnih koordinata (koordinate u koordinatnom sistemu snimka) istih tačaka na oba snimka velikog broja tačaka po jedinici površine terena i njihovo dalje procesuiranje.

Suština ovog automatskog merenja pojedinačnih (istih) tačaka na oba snimka leži u upoređivanju male matrice poksela leve slike sa matricom piksela desne slike stereopara i sukcesivnim računanjem "koeficijenta korelacije" (1):

$$
\rho_{g, g_{1}}=\frac{\sigma_{g_{1} g_{2}}}{\sqrt{\sigma_{g_{1}}^{2} \cdot \sigma_{g_{2}}^{2}}}=\frac{\sum_{r=1}^{R} \sum_{k=1}^{K}\left[g_{1}(r, k)-\mu_{1}\right] \cdot\left[g_{2}(r, k)-\mu_{2}\right]}{\sqrt{\left[\sum_{r=1}^{R} \sum_{k=1}^{K}\left\{g_{1}(r, k)-\mu_{1}\right\}^{2}\right] \cdot\left[\sum_{r=1}^{R} \sum_{k=1}^{K}\left\{g_{2}(r, k)-\mu_{2}\right\}^{2}\right]}}
$$

Ako je koeficijen korelacije, dva položaja male matrice piksela leve i desene slike, blizak jedinici (ali ne jednak ili veći od 1) automatski se ta mesta registruju (u memoriji računara) kao izmerene vrednosti slikovnih koordinata leve $\left(x_{i}^{\prime}, y_{i}^{\prime}\right)$ i desne $\left(x_{i}^{\prime \prime}, y_{i}^{\prime \prime}\right)$ slike jedne te iste tačke.

Dalje se ovako automatski izmerene slikovne koordinata istih tačaka para snimaka uvršćuju u jednačine kolinearnog preslikavanja, čime se definiše preslikavanje tačaka iz ravni snimka u prostorni koordinatni sistem (2). Tako se formira zrak preslikavanja za svaku izmerenu tačku tj. snop zraka (Sl.13) za sve tačke koje su izmerene na ovaj automatski način.

$$
\begin{aligned}
& x^{\prime}=x_{0}{ }^{\prime}-c \frac{a_{1}\left(X-X_{0}\right)+a_{2}\left(Y-Z_{0}\right)+a_{3}\left(Z-Z_{0}\right)}{a_{3}\left(X-X_{0}\right)+a_{3}\left(Y-Y_{0}\right)+a_{3}\left(Z-Z_{0}\right)} \\
& y^{\prime}=y_{0}{ }^{\prime}-c \frac{a_{2}\left(X-X_{0}\right)+a_{2}\left(Y-Z_{0}\right)+a_{3}\left(Z-Z_{0}\right)}{a_{3}\left(X-X_{0}\right)+a_{3}\left(Y-Y_{0}\right)+a_{3}\left(Z-Z_{0}\right)}
\end{aligned}
$$

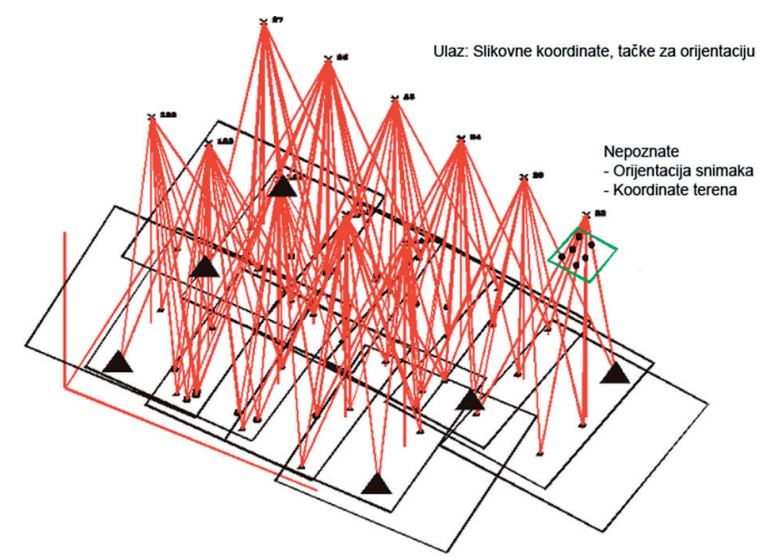

Sl.13 - zrakovni snop za blok aerosnimka[2] 
Ovaj zrakovni snop daje jednačine popravaka (3) iz kojih se formira sistem normalnih jednačina (4):

$$
\mathbf{V}=\mathbf{A x}-\mathbf{1}
$$

$$
\begin{aligned}
& \mathbf{N} \mathbf{x}=\mathbf{n} \\
& x=N^{-1} \cdot n
\end{aligned}
$$

čijim rešavanjem (5) se dobijaju prostorne koordinate $\left(X_{i}, Y_{i}, Z_{i}\right)$ svih tačaka koje su korelacijom merene na snimcima. S obzirom da je na ovaj način za svaki par snimaka određen ogroman broj tačaka po jedinici površine snimljenog terena, skup ovakvih tačaka nazivaju se „oblakom „..(Sl.14).

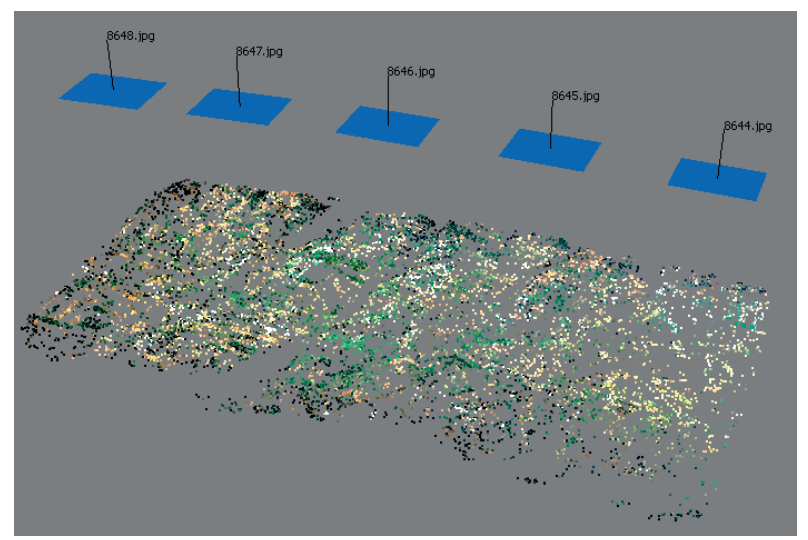

Sl.14 - oblak tačaka dobijenih iz automatske korelacije niza aerosnimaka

Automatskom interpolacijom ovog oblaka tačaka dolazi se do digitalnog modela terena (DMT) ili digitalnog površinskog modela (DPM).
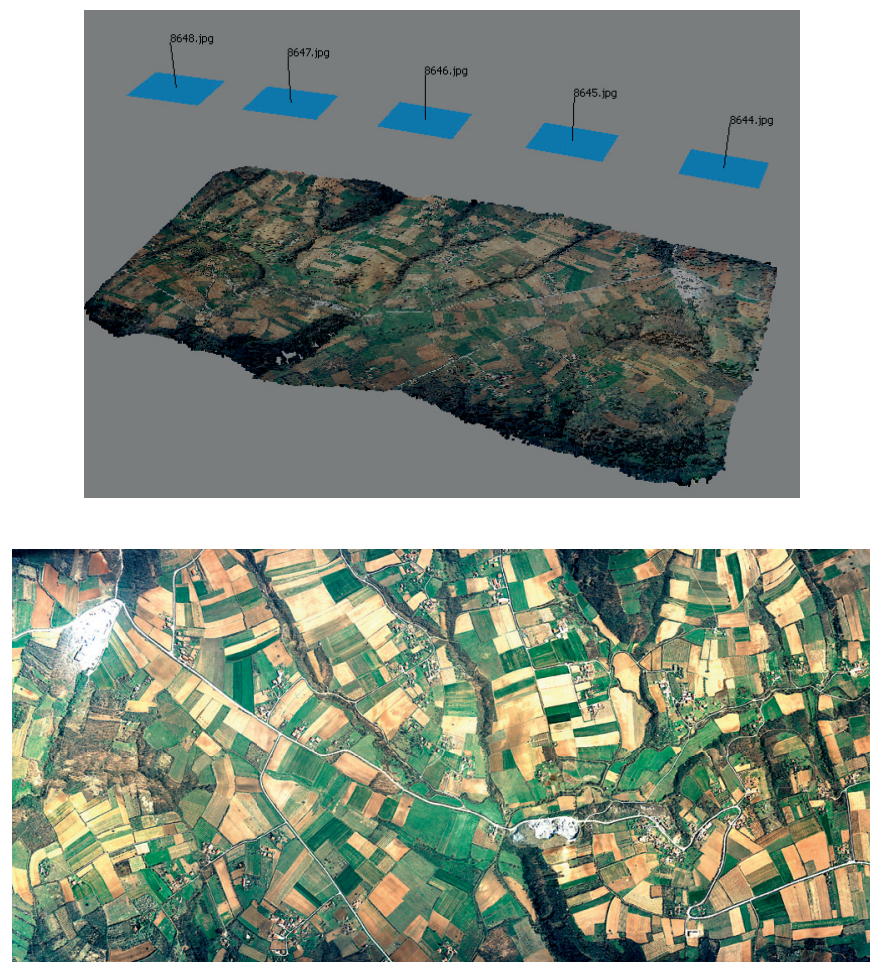

Sl.15 - oblak tačaka i DTM S1.16 - digitalni ortofoto

Razvijeni su i sistemi za automatsku aktuelizaciju i verifikaciju geoinformacija koje ulaze u baze podataka GISa. Suština postupka je automatsko upoređenje postojeće baze geoinforamacija sa aktuelnim digitalnim ortofotoom (Sl.18) odnosnog terena, dobijenim iz aero i satelitskih snimaka visoke rezolucije.

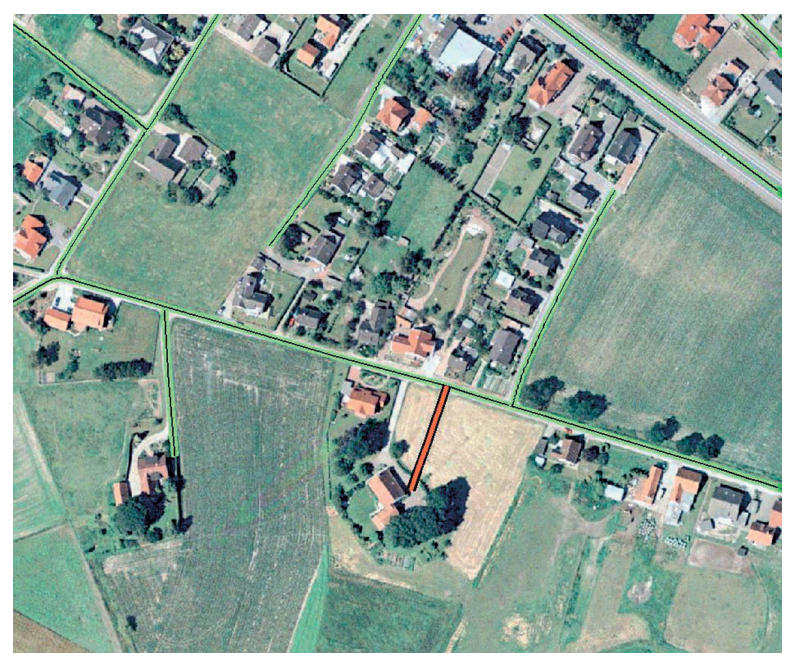

Sl.18 - primer automatske aktuelizacije podataka uz pomoć ortofotoa

Takođe se intenzivno razvijaju automatske metode ekstrakcije geoprostornih podataka iz satelitskih, radarskih i aero snimaka, i to:

- ekstarakcija puteva u cilju aktuelizacije GIS-a (Sl.19),

- automatska interpretacija poljoprivrednih površina na osnovu multispektralnih aerosnimka,

- dobijanje i analiza digitalnog modela terena u urbanim oblastima, itd.

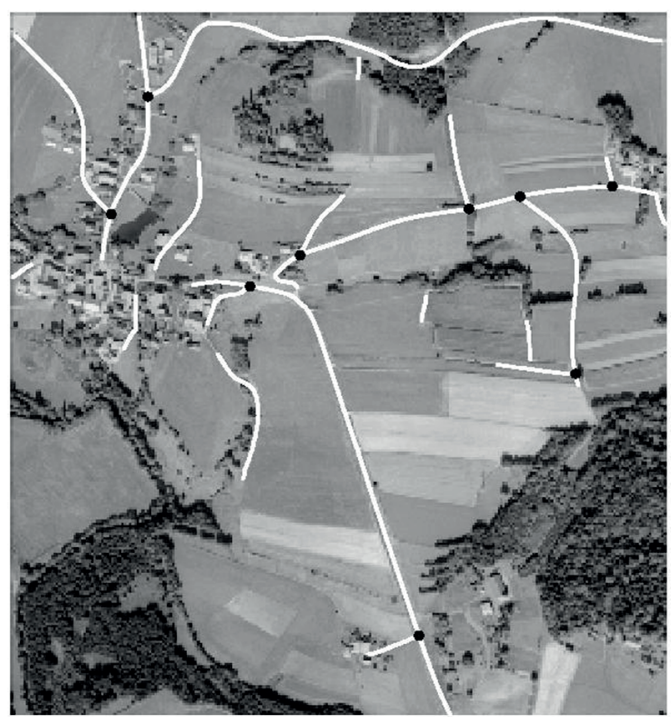

Sl.19 - primer automatske ekstrakcije puteva iz satelitskih snimaka [1]

\section{ZAKLJUČAK}

Pri izradi nekog geografskog informacionog sistema najvažniji njegov deo su baze podataka o prostoru na koji se taj GIS odnosi.

Masovno prikupljanje geoinformacija najbrže i najekonomičnije se izvodi merenjem i analizom digitalnih satelitskih, aero i terestričkih snimaka Zemljine površine. 
Digitalna fotogrametrija razvija poluautomatske i automatske metode i odgovarajuće software za ekstrakciju geoprostornih podataka, njihovu analizu i interpretaciju.

\section{LITERATURA}

[1] Markus Gerke, Dietmar Grunreich, Christian Heipke, Claus-Eberhard Liedtke \& Sonke Muller, "Automatisierte Verifikation topographischer Geoinformation unter Nutzung optischer Fernerkundungsdaten:Systemdesign und prakticshe Ergebnisse" Photogrammetrie • Fernerkundung - Geoinformation 2/2005, S. 111-122, 4 Abb., 4 Tab
[2] Jacobsen, K. "Integrated Sensor Orientation", EuroSDR Education Service, Budimpešta, 2004.

[3] Konecny, G „Geoinformation-Remote Sensing, Photogrammetry and Geographic Information Systems“,Taylor and Francis, London,2002.

[4] Alberz, J. „Fernerkundung“, Naučna knjiga, Berlin 2001.

[5] Marčeta,M. „Fotoframetrija i daljinska detekcija“,Visoka građevinsko-geodetska škola, Beograd 2007.

\section{COLLECTION OF INFORMATION FOR THE PRODUCTION OF GIS USING THE METHODS OF AUTOMATIC}

\section{Abstract:}

Geographic Information System (GIS) is a computerized system for the collection, analysis and management of geospatial data. Information about the area, placed in an appropriate database, are the main component of GIS. Mass acquisition of geospatial data is most economically and fastest done using the methods of photogrammetry. Today, automatic methods of digital photogrammetry are being intensively developed, to collect geospatial information about the area.

\section{Key words:}

Geospatial Information System, digital photogrammetry, image matching, digital terrain model. 